\title{
Comparative Study on the Mechanical Strength of SAP Internally Cured Concrete
}

\author{
Faxiang Xie ${ }^{1 *}$, Chuanlong Zhang ${ }^{1}$, Dingpeng Cai ${ }^{1 *}$ and Jing Ruan ${ }^{2}$ \\ ${ }^{1}$ College of civil and transportation Engineering, Hohai University, Nanjing, China, ${ }^{2}$ Jiangsu Provincial Communication \\ Construction Bureau, Nanjing, China
}

To investigate the relationships between the different mechanical strengths of internally cured concrete with Super Absorbent Polymer (SAP concrete), the uniaxial mechanical properties of SAP concrete with different internal curing water-cement ratios were studied. Various SAP concrete specimens were prepared, and the uniaxial compressive, splitting tensile, as well as four-point bending tests, were carried out using the electro-hydraulic servo testing machine. The cubic compressive strength, splitting tensile strength, and flexural strength of SAP concrete with different internal curing water-cement ratios was obtained. The converting relationships between the internal curing water-cement ratio and

OPEN ACCESS

Edited by:

Shengwen Tang,

Wuhan University, China

Reviewed by:

Xiao Qin,

Foshan University, China

Lei Wang,

Xi'an University of Architecture and

Technology, China

*Correspondence:

Faxiang Xie

xiefaxiang@vip.163.com

Dingpeng $\mathrm{Cal}$

191304040004@hhu.edu.cn

Specialty section:

This article was submitted to

Structural Materials,

a section of the journal

Frontiers in Materials

Received: 28 July 2020 Accepted: 09 October 2020

Published: 24 November 2020

Citation:

Xie F, Zhang C, Cai D and Ruan J (2020) Comparative Study on the Mechanical Strength of SAP Internally

Cured Concrete.

Front. Mater. 7:588130.

doi: 10.3389/fmats.2020.588130 different mechanical strengths were analyzed extensively. Based on the conversion formulas of different strength indexes proposed by different national standards and other researchers, the equations among the splitting tensile strength, cubic compressive strength, and flexural strength of SAP concrete were proposed and verified using the experimental data. According to the comparative analysis results, the proposed equations in this study have significant applicability and can be conducted in the practical application of SAP concrete.

Keywords: internally cured concrete, super absorbent polymer, flexural strength, compressive strength, splitting tensile strength, mechanical strength

\section{INTRODUCTION}

The internal curing of concrete occurs when the pre-absorbed materials are dispersed inside the concrete, preventing the rapid loss of internal humidity and maintaining a fully hydrated concrete. Philleo (1991) proposed the first application of lightweight aggregate in providing additional moisture for the curing of high-strength concrete in 1991, and developed the concept of internal curing concrete. Later, the International Union of Laboratories and Experts in Construction Materials, Systems and Structures (RILEM) (Mechtcherine, 2012) in 2003 described the internal curing of concrete as the introduction of additional water into the concrete for curing.

The early-stage internal curing materials are inorganic porous materials with lightweight aggregates (LWA) in most cases. However, the size of the LWA is too large, and the water absorption capacity is limited. Thus, it is not an ideal internal curing material for concrete. Moreover, the addition of LWA adversely affects the strength and elastic modulus of concrete. To solve this problem, Danish scholars Jensen and Hansen (2001) proposed the addition of superabsorbent polymer (SAP) to the concrete for a more efficient internal curing effect. SAP is a polymer compound that has super water absorption and retention capacities. It hydrates through its carboxyl and hydroxyl groups, rapidly absorbs water tens of times or even thousands of times its 
weight, and becomes gelatinous after absorbing water (Weng et al., 2002). Further, the SAP gel has great water-retaining properties and can slowly release the absorbed water in concrete. Consequently, it prevents early-age autogenous shrinkage of concrete and achieves an internal curing effect.

Due to its excellent water retentive performance (Mechtcherine, 2016), SAP has attracted a lot of research attention on its application as a curing agent in concrete. Consequently, many scholars have conducted studies on earlyage shrinkage and deformation of concrete. A study by Jensen and Hansen (2002) through ASTM specifications found that the early-age shrinkage deformation of the cement slurry disappeared after being mixed with SAP. Craeye et al. (2011) studied the autogenous shrinkage of SAP concrete under different water content. They found that the autogenous shrinkage of concrete can be reduced by $43 \%$ after $144 \mathrm{~h}$ after incorporating SAP. In a study on early-age autogenous shrinkage of SAP concrete, Shen et al. (2016) found an obvious shrinkage decline at the third and the seventh day. Furthermore, Kong and Zhang (2014) proposed that SAP reduced the shrinkage stress and early-age self-shrinkage by delaying loss of relative humidity inside the concrete in highstrength concrete.

Although the addition of SAP has been confirmed to have the ability to significantly decrease the autogenous shrinkage of earlyage concrete, its effect on the strength of concrete cannot be overlooked. Several studies have been conducted on the mechanical properties of SAP concrete with different amounts of SAP. By studying the compressive strength of SAP mortar, Jensen and Hansen (2002) found that the strength of SAP concrete was reduced by about $19 \%$. In a study on the mechanical strength of high-strength concrete (Craeye et al., 2011), an increase in SAP content was revealed to reduce the compressive strength and the splitting tensile strength by $27 \%$ and 33\%, respectively. In another study by Liu et al. (2020) on the mechanical strength of UHPC at 0.18 water-cement ratio, the flexural strength was decreased by $12.6 \%$ in 3 days, $4.1 \%$ in 28 days, and $6.3 \%$ in 56 days as the SAP content increased from 0 to $0.6 \%$, by mass of the binder. Moreover, studies by Guo (2016), Zhang (2019), and Ma (2015) found that increasing SAP content in ordinary concrete reduced its compressive strength up to $22 \%, 23 \%$, and $19 \%$, respectively. Hu et al. (2008) and other studies found that pre-absorbed SAP reduced the autogenous shrinkage of concrete, but its compressive strength was reduced notably when the SAP content is higher than $0.5 \%$. The reduction in mechanical strength due to SAP incorporation in concrete can be attributed to the following causes: on the one hand, it is because the free water in SAP is slowly released when the concrete hardens. After the SAP particles lose water, a large number of honeycomb holes are left in the hardened concrete stones, thus reducing the effective cross-sectional area. The pore structure of SAP concrete has been modified by SAP particles, similar to the effects caused by fly ash, silica fume and other additive admixtures (Wang et al., 2020a; Wang et al., 2020b; Wang et al., 2020c). At the same time, it easily causes stress concentration when the concrete specimen is compressed. This phenomenon increases the generation and development of micro-cracks inside the hardened concrete, thus reducing the concrete strength. On the other hand, the extra water from the SAP increases the total water-cement ratio of the concrete, hence lowering the mechanical strength.

In summary, adding SAP to concrete improves the resistance to early-age self-shrinkage of concrete significantly, but degrades its mechanical properties. Although many researchers have tested the uniaxial strength of SAP concrete, there are few reports on the conversions among different mechanical properties. Besides, it is difficult to measure all the mechanical strengths of SAP concrete in actual engineering site due to limited test conditions. Nevertheless, multiple strengths, such as the compressive strength and tensile strength, are necessary for most designs. Therefore, it is important to establish a conversion relationship between different mechanical performance indexes. In this study, for the SAP with chemical polymer (such as sodium polyacrylate) as the main material and water absorption ratio of $20-30 \mathrm{~g} / \mathrm{g}$, and concrete with an effective water-cement ratio between 0.32 and 0.55 , the mechanical conversion equations between various strengths were proposed, including the splitting tensile strength, cubic compressive strength, and flexural strength. These equations were based on the uniaxial compressive, uniaxial splitting tensile, and four-point bending tests of SAP concrete, in combination with domestic and foreign common concrete structural design codes (American Committee Institute, 2014; European Committee for Standardization, 2004; International Federation for Structural Concrete, 2010; Ministry of Transport of the People's Republic of China, 2014) as well as the proposals of Xiao and Li (2005), and Li et al. (2019). The equations between the mechanical properties of SAP concrete were verified with the experimental data obtained in this study and data from other researchers (Ma, 2015; Guo, 2016; Zhang, 2019). After the comparison and analysis, the proposed formulas proved the potential applicability and could provide useful references for the practical application of SAP concrete.

\section{EXPERIMENTAL PROGRAMS}

\section{The Concrete Mixing Ratio}

The initial design strength of the concrete without SAP was C40. Ordinary P.O.42.5 cement and natural river sand were used as binding material and fine aggregate, respectively. Limestone particles with a maximum particle size of $20 \mathrm{~mm}$ were adopted as the coarse aggregates, and city tap water was used as the mixer. The optimal internal curing water of the SAP agent was determined via the Power equation.

Powers and Brownyard (1946) proposed that the cement particles can be fully hydrated if the effective water-cement ratio is larger than 0.42 . When the water-cement ratio is less than 0.42 , the incorporated internal curing water-cement ratio could be calculated by Eq. 1 to ensure the full hydration of cementitious material:

$$
W_{i c} / C= \begin{cases}0.18 W / C & \text { for } W / C \leq 0.36 \\ 0.42-W / C & \text { for } 0.36 \leq W / C \leq 0.42\end{cases}
$$


TABLE 1 | The mixing proportions of various SAP concretes $\left(\mathrm{kg} / \mathrm{m}^{3}\right)$.

\begin{tabular}{|c|c|c|c|c|c|c|c|c|c|}
\hline Item & W/C & $\mathbf{W}_{\mathrm{ic}} / \mathbf{C}$ & Cement & Water & Sand & $\begin{array}{c}\text { Coarse } \\
\text { aggregate }\end{array}$ & SAP & $\begin{array}{c}\text { Internal } \\
\text { curing } \\
\text { water }\end{array}$ & $\begin{array}{l}\text { Water } \\
\text { reduction } \\
\text { agent }\end{array}$ \\
\hline SAP-0 & 0.323 & 0.000 & 480 & 155 & 640 & 1,160 & - & 0 & 0.5 \\
\hline SAP-6\% & 0.323 & 0.058 & 480 & 155 & 640 & 1,160 & 1.116 & 27.9 & 0.5 \\
\hline SAP-12\% & 0.323 & 0.116 & 480 & 155 & 640 & 1,160 & 2.232 & 55.8 & 0.5 \\
\hline SAP-17\% & 0.323 & 0.174 & 480 & 155 & 640 & 1,160 & 3.348 & 83.7 & 0.5 \\
\hline SAP-23\% & 0.323 & 0.233 & 480 & 155 & 640 & 1,160 & 4.464 & 111.6 & 0.5 \\
\hline
\end{tabular}

where $W_{i c} / C$ is the internal curing water-cement ratio and $W / C$ is the initial water-cement ratio.

According to Eq. 1, once the initial water-cement ratio $W / C$ equals to 0.323 , the required internal curing water-cement ratio for SAP is 0.058 . Five concrete mix proportions were designed to analyze the influence of varying SAP contents on the mechanical properties of concrete. The internal curing water-cement ratio was designed as $0,5.8 \%, 11.6 \%, 17.4 \%$, and $23.3 \%$, denoted as SAP- $0 \%$, SAP-6\%, SAP-12\%, SAP-17\%, and SAP-23\%, respectively in the subsequent sections. The mass of the internal curing agent can be calculated by the following steps: 1) calculating the internal curing water-cement ratio. For SAP-6\%, it is 0.058. 2) calculating the mass of internal curing water, which is 0.058 times the mass of cement, equal to $27.9 \mathrm{~kg} / \mathrm{m}^{3}$. 3) calculating the mass of the SAP agent. The absorption rate of SAP in the saturated solution of sodium carbonate is taken as $25 \mathrm{~g} / \mathrm{g}$. So the mass of SAP is $27.9 / 25=1.116 \mathrm{~kg} / \mathrm{m}^{3}$. Following the above steps, the mass of SAP of SAP- $12 \%$, SAP- $17 \%$, SAP- $23 \%$ can also be obtained. The five mixing proportions of concrete are listed in Table $\mathbf{1 .}$

Jensen and Hansen (2002) demonstrated that SAP with a particle size of about $100 \mu \mathrm{m}$ had the best effect on reducing autogenous shrinkage. RILEM (Wyrzykowski et al., 2018) suggested that dry SAP particles of small size should be added to concrete along with additional mixing water, which subsequently absorbs SAP upon mixing. Sodium polyacrylate SAP is one of the most commonly used types of SAP. It has a series of advantages, such as low production cost, simple manufacturing process, high production efficiency, high water absorption capacity, and long shelf life. Sodium polyacrylate SAP particles with an average size of $100 \mu \mathrm{m}$ were utilized in this study. The chemical composition of the SAP in this study includes $88 \%$ low cross-linking sodium polyacrylate (with $24.5 \%$ natrium), $8 \%-10 \%$ water, and $0.5 \%-1.0 \%$ cross-linking agent. The physical properties of the SAP used in this work are listed in Table 2. The dry and absorbent states of SAP are shown in Figure $\mathbf{1 .}$

Based on the methods chosen by other scholars (Ma, 2015; Guo, 2016; Zhang, 2019), the dry SAP particles were initially mixed with the dry cement with continuous stirring to distribute them evenly. Subsequently, water was slowly added (including internal curing water) before pouring the cementitious mixture into the molds, and the specimen were placed in a standard curing room. After completing the curing period (28 days), the specimens were then taken out for mechanical testing.

\section{Experimental Programs}

The mechanical performance tests of the SAP concrete conducted in this paper include cubic compressive test, splitting tensile test, and four-point bending test. The specimen used in the cubic compressive tests and the splitting tensile test was with a size of $100 \times 100 \times$ $100 \mathrm{~mm}$. The size of the specimens used in the four-point bending test was $100 \times 100 \times 400 \mathrm{~mm}$. Three test pieces were adopted for each test to ensure the reliability of the results. The detailed experimental programs and specimens are listed in Table 3.

\section{The Loading Equipment and Methods}

The compressive test was completed using the WAW-E2000 electro-hydraulic servo machine (Jinan Test Machine Factory). The loading method was based on Chinese standard GB/T 500812002 i.e., Standard for Mechanical Test Methods for Ordinary Concrete (Ministry of Housing and Urban-Rural Development of the People's Republic of China \& General Administration of Quality Supervision, Inspection and Quarantine of the People's Republic of China, 2003), as illustrated in Figure 2A. The loading procedure was stress-controlled at a loading rate of $0.5 \mathrm{MPa} / \mathrm{s}$. The load and the displacement of the machine chuck were recorded until the specimen failed. The compressive strength of the SAP concrete was calculated via Eq. 2:

$$
f_{c u}=\frac{F_{c}}{A}
$$

where $F_{c}$ is the failure load $(\mathrm{N})$ of the specimen, $\mathrm{A}$ is the bearing area $\left(\mathrm{mm}^{2}\right)$, and $f_{c u}$ is the compressive strength $(\mathrm{MPa})$.

Since non-standard samples were used in this study, the compressive strength calculated according to Eq. 2 was multiplied by the dimension conversion factor of 0.95 according to the specification.

TABLE 2 | Properties of internal curing agent SAP.

\begin{tabular}{|c|c|c|c|c|c|c|}
\hline Dimension $(\mu \mathrm{m})$ & Density $\left(\mathrm{kg} / \mathrm{m}^{3}\right)$ & $\begin{array}{c}\text { Water absorbing } \\
\text { capacity (Pure } \\
\text { water) }\end{array}$ & $\begin{array}{c}\text { Water absorbing } \\
\text { capacity (NaCl } \\
9 \%)\end{array}$ & $\begin{array}{l}\text { Water absorbing } \\
\text { capacity in } \\
\text { a minute } \\
(\mathbf{g} / \mathbf{g})\end{array}$ & $\mathrm{pH}$ & Water-content $(/ \%)$ \\
\hline
\end{tabular}




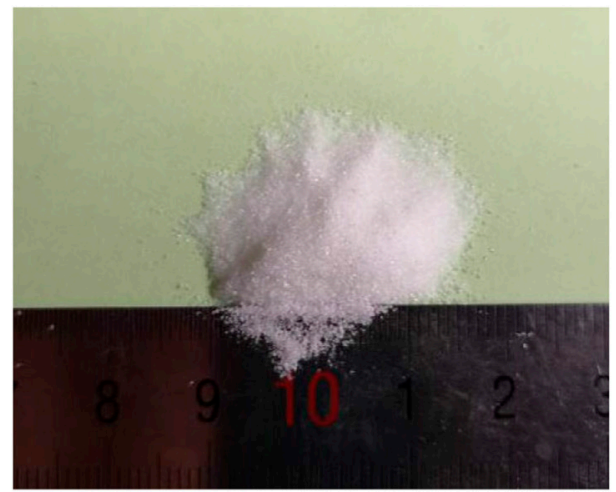

Dry SAP particles

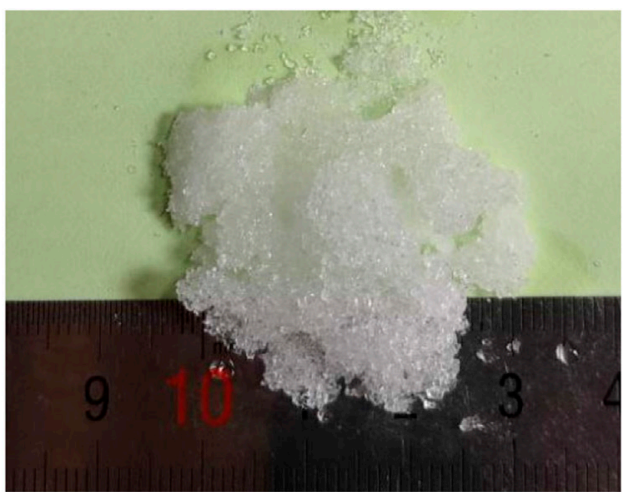

Wet SAP particles

FIGURE 1 | The experimental SAP particles in experiments. (A) Dry SAP particles and (B) Wet SAP particles.

The uniaxial splitting tensile test of concrete was completed using the RE-8060 electro-hydraulic servo machine (Shenzhen Regal Instrument Co., Ltd). The load rate was $0.05 \mathrm{MPa} / \mathrm{s}$. The loading process was stopped when the sample failed. The loading diagram is shown in Figure 2B. The load and displacement were recorded until the specimen failed. The splitting tensile strength of SAP concrete was calculated according to Eq. 3:

$$
f_{s p}=0.637 \frac{F_{s}}{A}
$$

where $F_{s}$ is the failure load $(\mathrm{N})$ of the specimen, $\mathrm{A}$ is the splitting area $\left(\mathrm{mm}^{2}\right)$, and $f_{s p}$ is the splitting tensile strength (MPa) of the SAP concrete.

Since non-standard samples were utilized in the tests, the splitting tensile strength calculated according to Eq. 3 was multiplied by the dimension conversion factor of 0.85 according to the specification.

The four-point bending tests of the SAP concrete were carried out by the MTS322 hydraulic servo machine. The loading method used was based on the Chinese GB/T 50081-2002 Standard for Mechanical Test Methods for Ordinary Concrete (Ministry of Housing and Urban-Rural Development of the People's Republic of China \& General Administration of Quality Supervision, Inspection and Quarantine of the People's Republic of China, 2003). The load was controlled by stress at a rate of $0.05 \mathrm{MPa} / \mathrm{s}$. The loading schematic diagram is shown in Figure 2C. The test loads during the failure of the specimen were recorded, and the flexural strength of SAP concrete calculated according to Eq. 4:

$$
f_{f}=\frac{F_{b} l}{b h^{2}}
$$

where $F_{b}$ is the failure load (N) of the sample, $L$ is the span between the supports ( $\mathrm{mm}), b$ is the section width $(\mathrm{mm})$, and $h$ is the section height of the sample, and $f_{f}$ is the flexural strength of the concrete (MPa).

Since the non-standard specimen size of $100 \times 100 \times 400 \mathrm{~mm}$ was used in this work, the flexural strength calculated was multiplied by the size conversion factor of 0.85 according to the Chinese code.

\section{RESULTS AND ANALYSIS}

\section{Strength Variation With SAP Content}

Typically, SAP and incorporated internal water increase the total water-cement ratio of the concrete. Although SAP has the waterholding capacity, the additional water from SAP increases the total water-cement ratio, thus affecting the long-term strength of concrete. The experimental results of the compressive, splitting tensile, and flexural strength of concrete with different mix ratios are summarized in Table 4.

Through mathematical fitting analysis, the following equations were obtained to fit the relationship between SAP

\begin{tabular}{|c|c|c|c|}
\hline Item & Loading profile & Size of specimen & $\begin{array}{c}\text { Number of the } \\
\text { test } \\
\text { piece }\end{array}$ \\
\hline $\begin{array}{l}\text { SAP-0\%- } \\
\text { comp }\end{array}$ & $\begin{array}{l}\text { Uniaxial } \\
\text { compression }\end{array}$ & $100 \times 100 \times 100 \mathrm{~mm}$ & 3 \\
\hline $\begin{array}{l}\text { SAP-6\%- } \\
\text { comp }\end{array}$ & $\begin{array}{l}\text { Uniaxial } \\
\text { compression }\end{array}$ & $100 \times 100 \times 100 \mathrm{~mm}$ & 3 \\
\hline $\begin{array}{l}\text { SAP-12\%- } \\
\text { comp }\end{array}$ & $\begin{array}{l}\text { Uniaxial } \\
\text { compression }\end{array}$ & $100 \times 100 \times 100 \mathrm{~mm}$ & 3 \\
\hline $\begin{array}{l}\text { SAP-17\%- } \\
\text { comp }\end{array}$ & $\begin{array}{l}\text { Uniaxial } \\
\text { compression }\end{array}$ & $100 \times 100 \times 100 \mathrm{~mm}$ & 3 \\
\hline $\begin{array}{l}\text { SAP-23\%- } \\
\text { comp }\end{array}$ & $\begin{array}{l}\text { Uniaxial } \\
\text { compression }\end{array}$ & $100 \times 100 \times 100 \mathrm{~mm}$ & 3 \\
\hline SAP-0\%-split & Split tension & $100 \times 100 \times 100 \mathrm{~mm}$ & 3 \\
\hline SAP-6\%-split & Split tension & $100 \times 100 \times 100 \mathrm{~mm}$ & 3 \\
\hline SAP-12\%-split & Split tension & $100 \times 100 \times 100 \mathrm{~mm}$ & 3 \\
\hline SAP-17\%-split & Split tension & $100 \times 100 \times 100 \mathrm{~mm}$ & 3 \\
\hline SAP-23\%-split & Split tension & $100 \times 100 \times 100 \mathrm{~mm}$ & 3 \\
\hline SAP-0\%-bend & Four-point bending & $100 \times 100 \times 400 \mathrm{~mm}$ & 3 \\
\hline SAP-6\%-bend & Four-point bending & $100 \times 100 \times 400 \mathrm{~mm}$ & 3 \\
\hline $\begin{array}{l}\text { SAP-12\%- } \\
\text { bend }\end{array}$ & Four-point bending & $100 \times 100 \times 400 \mathrm{~mm}$ & 3 \\
\hline $\begin{array}{l}\text { SAP-17\%- } \\
\text { bend }\end{array}$ & Four-point bending & $100 \times 100 \times 400 \mathrm{~mm}$ & 3 \\
\hline $\begin{array}{l}\text { SAP-23\%- } \\
\text { bend }\end{array}$ & Four-point bending & $100 \times 100 \times 400 \mathrm{~mm}$ & 3 \\
\hline
\end{tabular}
content and the corresponding strength of the SAP concrete: 


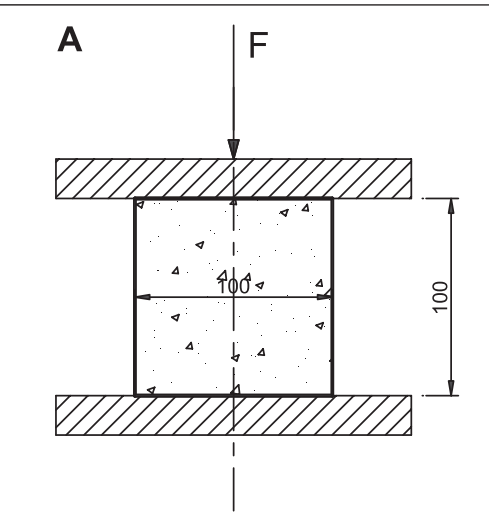

Compression test

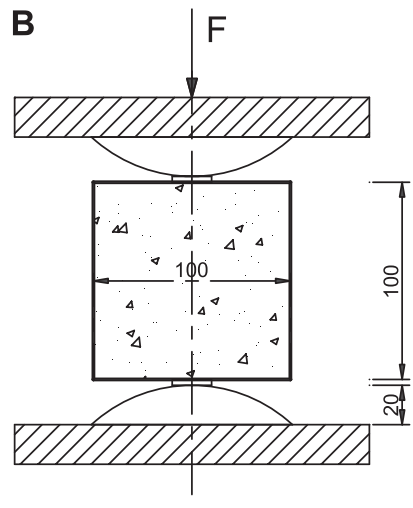

Splitting tension test

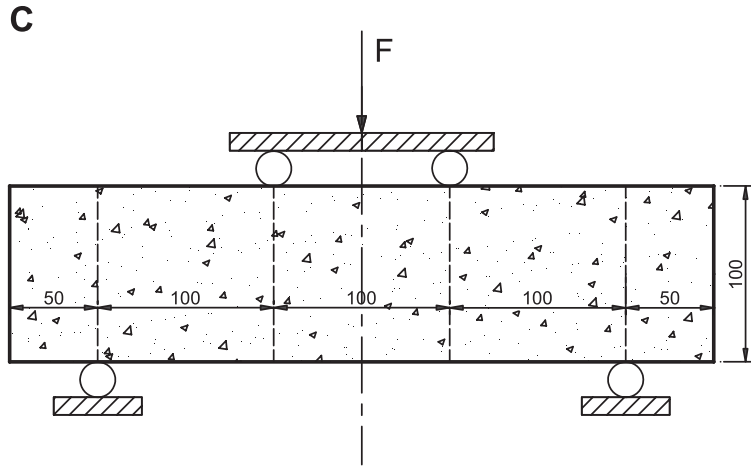

Four-point bending test

FIGURE 2 | Loading schematic diagram of experiments. (A) Compression test, (B) Splitting tension test, and (C) Four-point bending test.

TABLE 4 | Compressive, splitting tensile and flexural strength of SAP concrete at different mixing proportions.

Specimen

Cubic Compressive Strength (MPa)

SAP-0\%

SAP-6\%

SAP-12\%

SAP-17\%

SAP-23\%

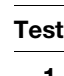

40.71

32.19

27.71

30.94

27.55

\begin{tabular}{|c|c|c|}
\hline Test 2 & Test 3 & Average \\
\hline 2 & 3 & 4 \\
\hline 40.04 & 40.64 & 40.46 \\
\hline 34.51 & 30.03 & 32.24 \\
\hline 28.12 & 30.30 & 28.71 \\
\hline 30.57 & 27.78 & 29.76 \\
\hline 21.05 & 24.23 & 24.28 \\
\hline
\end{tabular}

\begin{tabular}{|c|c|c|c|}
\hline \multicolumn{4}{|c|}{ Splitting tensile strength (MPa) } \\
\hline Test 1 & Test 2 & Test 3 & Average \\
\hline 5 & 6 & 7 & 8 \\
\hline 5.15 & 4.58 & 4.25 & 4.66 \\
\hline 4.58 & 4.22 & 4.48 & 4.43 \\
\hline 4.42 & 4.25 & 4.16 & 4.28 \\
\hline 4.30 & 3.91 & 3.70 & 3.97 \\
\hline 3.49 & 3.39 & 3.46 & 3.45 \\
\hline
\end{tabular}

\begin{tabular}{|c|c|c|c|}
\hline \multicolumn{4}{|c|}{ Flexural strength (MPa) } \\
\hline Test 1 & Test 2 & Test 3 & Average \\
\hline 9 & 10 & 11 & 12 \\
\hline 4.42 & 4.95 & 5.52 & 4.96 \\
\hline 4.34 & 5.01 & 4.72 & 4.69 \\
\hline 4.46 & 4.27 & 3.66 & 4.13 \\
\hline 3.95 & 3.76 & 3.90 & 3.86 \\
\hline 2.52 & 2.98 & 2.71 & 2.73 \\
\hline
\end{tabular}
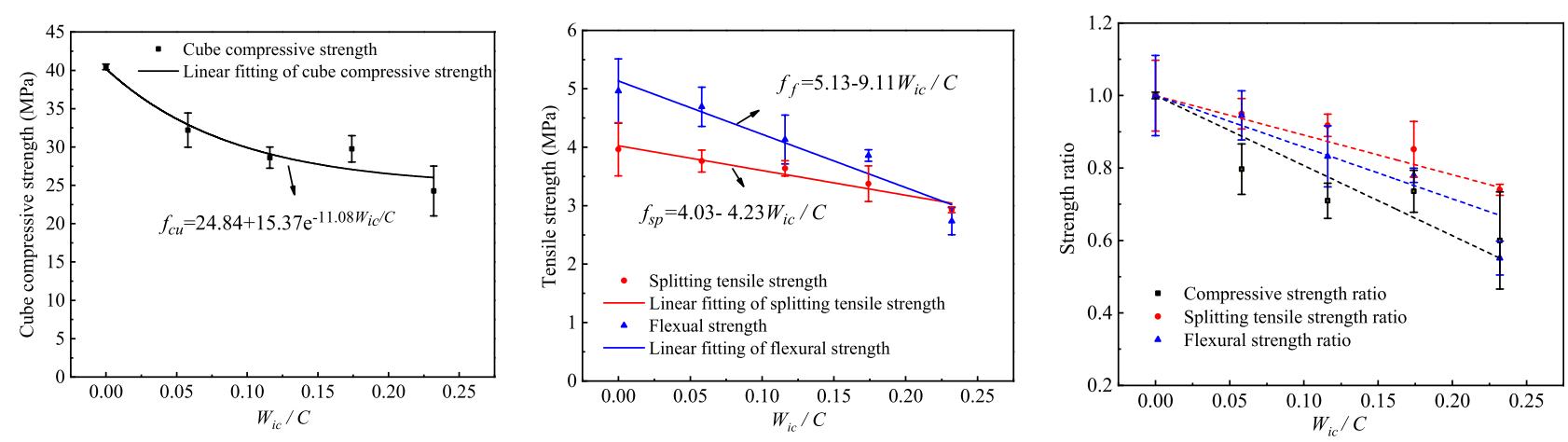

FIGURE 3 | Variation of uniaxial strength of concrete with different SAP content. (A) Relationship of cubic compressive strength and internal curing water-cement ratio, (B) Relationship of tensile strength and internal curing water-cement ratio, (C) Variation rate of uniaxial strength with different SAP content.

$$
\begin{array}{ccrl}
f_{c u} & =24.84+15.37 \cdot e^{-11.08 W_{i c} / C} & R^{2} & =0.85 \\
f_{s p} & =-4.23 \cdot W_{i c} / C+4.03 & R^{2} & =0.93 \\
f_{f} & =-9.11 \cdot W_{i c} / C+5.13 & R^{2} & =0.90
\end{array}
$$

where $W_{i c} / C$ is the internal water-cement ratio and $f_{c u}, f_{s p}$, and $f_{f}$ are the cubic compressive strength, splitting tensile strength, and flexural strength of concrete specimens, respectively.
The relationship between the strength and the variation of internal water content is plotted in Figure 3A. It can be observed that the compressive, splitting tensile and flexural strengths of SAP concrete were reduced due to the added SAP and internal curing water. Meanwhile, the decrease rate of the compressive strength and flexural strength is higher than the splitting tensile strength, showing in Figure 3B. The overall compressive strength and flexural strength of SAP concrete decreased by $40 \%$ and $45 \%$ in SAP $23 \%$, respectively. 
In contrast, the splitting tensile strength was decreased by only $26 \%$, as illustrated in Figure 3C. The research of Laila (Laila et al., 2020) also showed the same rule. For the concrete with 5\% replacement of cement by granite Pulver, with the addition of SAP, the overall compressive strength and splitting tensile strength decreased by $23 \%$ and $3 \%$ respectively, while the reduction of flexural strength reached $28 \%$. It is consistent with the results of this paper. Tong (Tong, 2018) also pointed out that SAP has a negative effect on the flexural strength of concrete or mortar. This can be attributed to the following facts: firstly, all the strength of SAP concrete decreases with the increase of SAP and internal curing water, which increasing the total watercement ratio. The higher water-cement ratio increases the porosity of the SAP concrete, and weakens the specimen section. Secondly, under uniaxial compressive stress, the concrete is easily cracked by stress concentration around the pores inside the SAP concrete, thus causing a decrease in compressive strength. Thirdly, the increase of the concrete void reduces the tensile strength for the weakened section. However, due to the formation of the organic film between the cement stone after the SAP loses water, the tensile strength of the concrete samples increased because of the embedded SAP film. Subsequently, the decreasing rate of the splitting tensile was slowed down. At the same time, the compressive strength can hardly benefit from the newly formed polymer film. According to RILEM (Mechtcherine et al., 2014), when SAP releases internal curing water, it shrinks and leaves air voids behind, which act as weak spots in the material structure, decreasing the flexural strength. Tong (2018) pointed out that the existence of pores due to the shrinkage of SAP is a kind of defect in the concrete. Considering the pros and cons from SAP, the compressive strength deceases the most and the splitting tensile strength the least while the flexural strength is in the middle, with the increase of SAP content.

\section{The Relationship Between Compressive Strength and Splitting Tensile Strength}

Generally, the compressive strength is correlated with the tensile strength of concrete. As the compressive strength of concrete increases, its tensile strength also increases. Due to the inhomogeneity of the interior structure and complexity of the uniaxial direct tensile test, the splitting tensile strength of concrete is mainly utilized to evaluate the tensile performance of different concretes rather than the axial tensile strength. Based on the theoretical and experimental results (Raphael, 1984), the splitting tensile strength is close to or slightly larger than the axial tensile strength. The tensile strength is the key index in structural design. Thus it is important to establish the relationship between the compressive and the splitting tensile strength for SAP concrete.

In China's "Code for Design of Concrete Structures (GB500102010)" (Ministry of housing and urban-rural development of the People's Republic of China [MOHURD], 2010), the standard value of axial tensile strength can be converted to the prism tensile strength of ordinary concrete by the following Eq. 8:

$$
f_{t k}=0.88 \times 0.395 f_{c u, k}(1-1.645 \delta)^{0.45} \times \alpha_{c 2}
$$

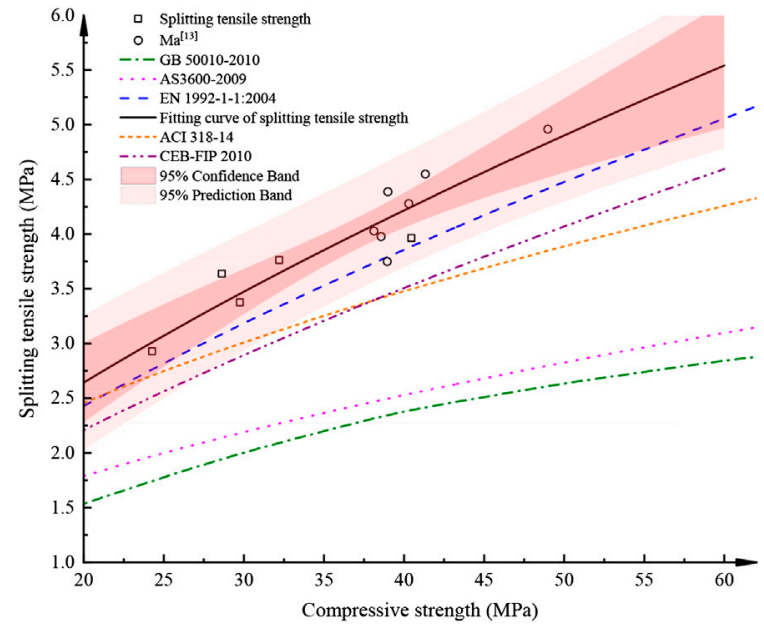

FIGURE 4 | The relationship of cubic compressive strength and splitting tensile strength of SAP concrete.

For C40 concrete, the brittle coefficient $\alpha_{c 2}$ is 1.0 and $\delta$ is the variation coefficient of the concrete.

In the "Australian Standard: Concrete Structure" (AS36002009) (Committee BD-002, 2009), the proposed relationship between the splitting tensile strength and compressive strength of ordinary concrete is:

$$
f_{c t, s p}=0.4 f_{c}^{0.5}
$$

In the "Eurocode 2:Design of concrete structure-Part 1-1" (EN 1992-1-1) (European Committee for Standardization, 2004), the conversion equation between the splitting tensile strength and compressive strength of ordinary concrete is as follows:

$$
f_{c t, s p}=0.33 f_{c k}^{0.67}
$$

The relationship between splitting tensile strength and compressive strength of ordinary concrete as proposed by American Concrete Institution (ACI 318-14) (American Committee Institute, 2014) is as follows Eq. 11:

$$
f_{s p}=0.55 f_{c k}^{0.5}
$$

According to the model code of the International Federation for Structural Concrete (International Federation for Structural Concrete, 2010) (CEB-FIP 2010), the relationship between splitting tensile strength and compressive strength of ordinary concrete is defined as:

$$
f_{c t, s p}=0.30 f_{c k}^{0.67}
$$

Based on the recommended equations between the splitting tensile strength and compressive strength in the design codes of 
TABLE 5 | The quasi flexure-compression ratio of SAP concrete.

\begin{tabular}{|c|c|c|c|}
\hline $\begin{array}{l}\text { Internal curing water-cement } \\
\text { ratio }\left(W_{i c} / C\right)\end{array}$ & Cubic compressive strength $f_{c u}$ & Flexural strength $\mathbf{f}_{\mathrm{f}}$ & $\mathbf{f}_{\mathbf{f}} / \sqrt{\mathbf{f}_{\mathrm{cu}}}$ \\
\hline 0.000 & 40.46 & 5.7221 & 0.8995 \\
\hline 0.058 & 32.21 & 5.4646 & 0.9628 \\
\hline 0.116 & 28.62 & 4.8907 & 0.9141 \\
\hline 0.174 & 29.76 & 4.5436 & 0.8329 \\
\hline 0.232 & 24.27 & 3.2174 & 0.6531 \\
\hline
\end{tabular}

the various countries, it can be found that the power function is widely used to describe the relationship between the two variables. The corresponding power index range is from $1 / 2$ to $2 / 3$. This fact demonstrates that, as the compressive strength of concrete increases, the growth rate of the splitting tensile strength gradually slows down. Besides, since concrete is a brittle material, the growth of splitting tensile strength has certain limitations. According to the equation given in the specification, combined the data in this paper and Ma's experimental data of SAP concrete ( $\mathrm{Ma}, 2015)$ which has a similar efficient water-cement ratio of 0.37 and strength of the SAP concrete, the following equation is proposed to describe the relationship of SAP concrete:

$$
f_{s p}=0.35 f_{c u}^{0.67} \quad R^{2}=0.83
$$

The test data and the fitting curve are plotted in Figure 4. according to the figure, the proposed power equation has a favorable agreement for the relationship between the compressive strength and splitting tensile strength. The recommended equation is closest to the European specifications. Both China's and the Australian specification are in the lower position in the figure. Since the equations in the national specifications adopt the standard value of concrete with a $95 \%$ guaranteed reliability, it may lead to conservative predictions. In general, as mentioned above, SAP concrete has a higher splitting tensile strength than ordinary concrete, and this is a valuable factor in practical engineering application.

\section{The Relationship Between the Compressive and Flexural Strength of SAP Concrete}

For the relationship of flexural strength and compressive strength of ordinary concrete, the following expression is proposed in ACI 318-14 (American Committee Institute, 2014)

$$
f_{f}=0.62 \sqrt{f_{c}}
$$

The relationship established by the AS3600-2009 (Committee BD-002, 2009) is expressed as:

$$
f_{f}=0.6 \sqrt{f_{c}}
$$

The flexural strength of ordinary concrete $f_{f}$ can be calculated from $\sqrt{f_{c u}}$. Besides, most of the national standards have established a linear relationship between the two parameters (the rate is referred to as quasi flexure-compression ratio). Table 5 shows the calculation of the quasi flexurecompression ratios of the different SAP concretes. According to the calculation results, SAP concrete has various features from ordinary concrete. As the SAP content changes, the quasi flexurecompression ratio of SAP concrete changes proportionally. Thus, the relationship between compressive strength and flexural strength of SAP concrete should depend on the incorporated SAP content (expressed by the internal curing water-cement ratio in this paper). Guo (2016) carried out uniaxial compressive and four-point bending tests for SAP concrete with an effective water-cement ratio of 0.32 . The internal curing water-cement ratio was $0-0.09$, with the designed water absorption rate of 20-30 g/g for SAP. Zhang (2019) carried out uniaxial compressive and four-point bending tests for SAP concrete with an effective water-cement ratio of 0.37 and an internal curing water-cement ratio of $0-0.15$. The cubic compressive strength and flexural strength of concrete with different SAP contents were obtained in the research. All SAP used in their experiments were chemical polymers, and the effective watercement ratio was similar to that in this paper. By integrating the data of Guo (2016), and Zhang (2019) on the strength of SAP concrete and incorporating the regression analysis with the data in this article, a more applicable equation can be obtained.

Referring to the rational form proposed by Xiao and Li (2005), the relationship equation between SAP concrete strength at different internal water-water-cement ratios is:

$$
f_{f}=d \sqrt{f_{c u}}\left(1+\frac{W_{i c} / C}{F\left(W_{i c} / C\right)}\right)
$$

where $F\left(W_{i c} / C\right)$ is the quadratic function $F\left(W_{i c} / C\right)=$ $a\left(W_{i c} / C\right)^{2}+b\left(W_{i c} / C\right)+c$. After the fitting analysis, the relationship between the flexural strength and compressive strength can be calculated as follows:

$$
\begin{aligned}
& f_{f} / \sqrt{f_{c u}} \\
& =0.86\left(1+\frac{W_{i c} / C}{-130.43\left(W_{i c} / C\right)^{2}+62.40\left(W_{i c} / C\right)-8.13}\right) \quad R^{2}=0.85
\end{aligned}
$$

The combined plot of test data and the fitting curve is shown in Figure. 5, marked as "Fitting curve 1." 


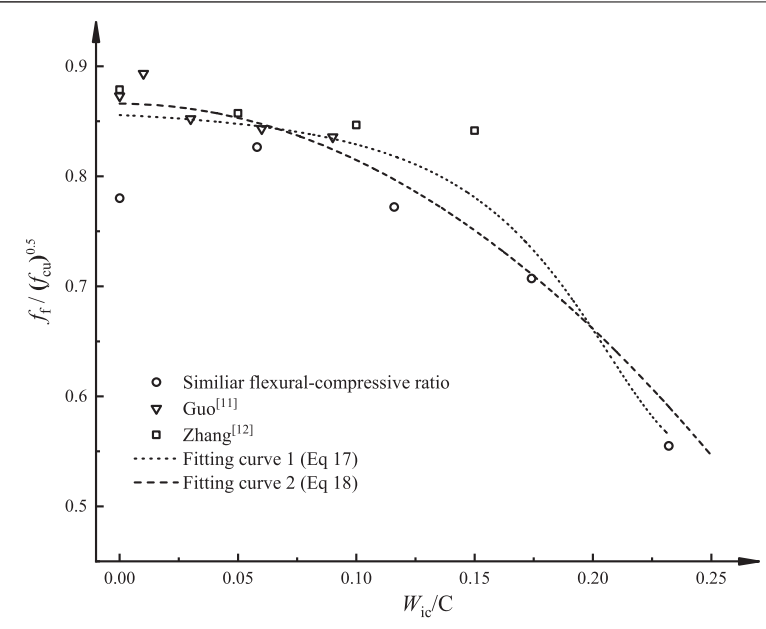

FIGURE $\mathbf{5}$ | The relationship of the internal curing water-cement ratio and $f_{f} /\left(f_{C U}\right)^{0.5}$.

In Figure 5, it is clear that, when the internal curing watercement ratio is small, the quasi flexure-compression ratio of SAP concrete remains nearly constant which is similar to the performance of ordinary concrete. After the internal curing water-cement ratio increases to 0.10 , the quasi flexurecompression ratio drops rapidly. This fact means that when the internal curing water-cement ratio $W_{i c} / C>0.10$, the flexural performance of the SAP concrete will decline rapidly. Moreover, at an internal curing water-cement ratio higher than 0.15 , the ratio is less than 0.7 . The negative influence will continue to increase as the SAP content increases. To compare the effect of different regression curves when negligible SAP concentration in concrete, the following quadratic polynomial equation is also proposed:

$$
f_{f} / \sqrt{f_{c u}}=0.87-5.12\left(W_{i c} / C\right)^{2} \quad R^{2}=0.80
$$

The obtained curve is plotted as "Fitting curve 2" as shown in Figure 5. By comparing the two fitting curves, it is clear that when the internal curing water-cement ratio increases, the fitting curve 2 (polynomial) gradually decreases throughout the entire $W_{i c} / C$ values. Besides, when the internal curing water-cement ratio is low, the fitting curve 1 (rational form) remains relatively stable and rapidly decreases when the value of the internal water-cement ratio increases. It is consistent with the recommendations of different countries' standards for ordinary concretes. This phenomenon indicates that Eq. 17 has potential applicability which is recommended as the conversion relationship between flexural strength and compressive strength of SAP concrete.

\section{The Relationship Between Splitting Tensile Strength and Flexural Strength}

The splitting tensile strength and flexural strength reflect the tensile properties of concrete, although these two strengths are different. There has a long-established concern that the splitting tensile strength is closer to the real tensile strength in a material. The experimental data show that the flexural strength often tends to be higher than the splitting tensile strength for the mutual restraint of longitudinal fibers in the tensile zone which increases the material tensile strength at the four-point bending tests (Zheng et al., 2001). The Chinese codes generally use splitting tensile strength instead of the flexural strength to present the axial tensile strength of concrete. However, due to the addition of SAP and internal curing water, the reduction rate of the flexural strength and splitting tensile strength of SAP concrete varies. Therefore, in SAP concrete, the conversion equation between these two strengths need to be further studied.

In China's “Technical Guidelines for Construction of Highway Cement Concrete Pavement" (JTG/T F30-2014) (Ministry of Transport of the People's Republic of China, 2014), the relationship equation between flexural strength and splitting tensile strength is proposed in the form of a power function as follows:

$$
f_{f}=1.868 f_{s p}^{0.871}
$$

The "Australian Standard: Concrete Structure" (AS36002009) (Committee BD-002, 2009) incorporates the linear relationship between the flexural strength and the splitting tensile strength, which is expressed as:

$$
f_{f}=1.5 f_{s p}
$$

The relationship between flexural strength and splitting tensile strength of ordinary concrete as proposed by the American Concrete Institution (ACI 318-14) (American Committee Institute, 2014) is:

$$
f_{f}=1.12 f_{s p}
$$

In the "Eurocode 2:Design of concrete structure-Part 1-1" (EN 1992-1-1) European model specification (European Committee for Standardization, 2004), the conversion equation between the flexural strength and the splitting tensile strength of ordinary concrete is as follows:

$$
f_{f}=1.35 f_{s p}
$$

The relationship between splitting tensile strength and compressive strength of the normal concrete proposed by the International Federation for Structural Concrete (CEB-FIP 2010) (International Federation for Structural Concrete, 2010) is:

$$
f_{f}=1.66 f_{s p}
$$

According to the experimental data of the flexural strength and the splitting tensile strength, the relationship is fitted by the linear model: 


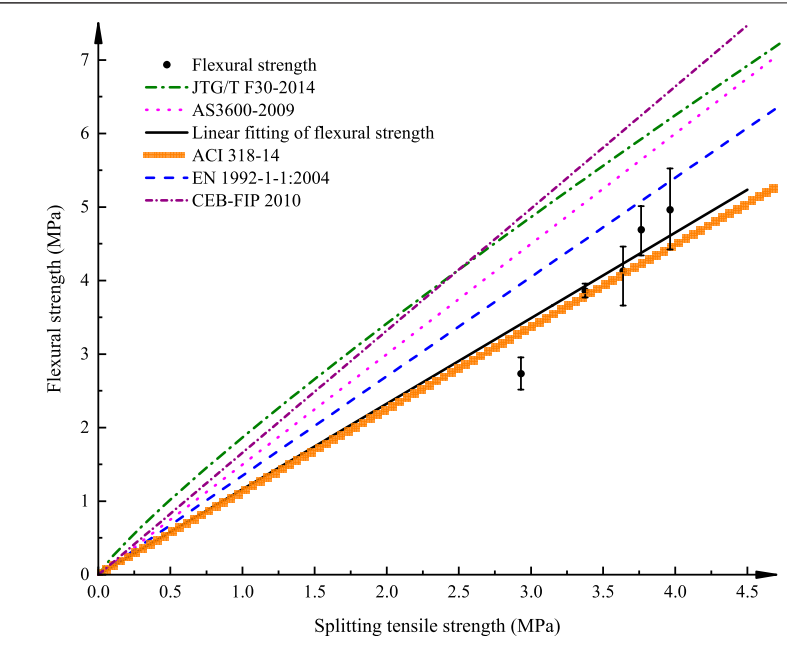

FIGURE 6 | The relationship between the splitting tensile strength and flexural strength. strength, and flexural strength of SAP concrete, which provided a reference for the practical engineering application of SAP concrete. For the similar SAP utilized in this study, and concrete with an effective water-cement ratio of concrete between 0.32 and 0.55 , the following conclusions can be drawn:

(1) The increase of SAP content in concrete decreases the compressive strength, splitting tensile strength, and flexural strength of the SAP concrete. Sequentially, as the content of SAP grows lager, the compressive strength decreases the fastest, followed by the flexural strength, and the splitting tensile strength is the slowest.

(2) Based on the different design codes of major countries, the conversion equation between the splitting tensile strength of SAP concrete and the compressive strength of SAP concrete can be calculated by Eq. 13 .

(3) By introducing the concept of the quasi flexure-compression ratio, the relationship among the flexural strength, compressive strength, and SAP content is proposed. When the internal curing water-cement ratio lower than 0.10 , the quasi flexurecompression ratio remains stable. As the internal curing watercement ratio rises to 0.15 , the quasi flexure-compression ratio starts to decline rapidly. The proposed equation reflects the relationship between the flexural strength and the compressive strength of SAP concrete correctly.

(4) A linear model can express the relationship between the flexural strength and splitting tensile strength of SAP concrete. Compared with the recommended equations by the global specifications, the flexural strength under the same splitting tensile strength of SAP concrete is lower. Calculating the flexural performance of SAP concrete from current specifications might lead to an overestimation of the flexural strength. The weakening of the flexural strength exhibited in SAP concrete needs to be considered to obtain a safe design.

\section{DATA AVAILABILITY STATEMENT}

The original contributions presented in the study are included in the article/supplementary materials, further inquiries can be directed to the corresponding author/s.

\section{AUTHOR CONTRIBUTIONS}

FX initialized the idea of the study and wrote the manuscript. DC carried out the experiment and analyze the data. CZ complemented the experiments and the experimental data. JR provided the necessary resources.
This paper studied the influence of SAP on the mechanical strengths of concrete and proposed the conversion equations among the splitting tensile strength, cubic compressive 


\section{REFERENCES}

American Committee Institute (2014). ACI 318-14: Building code requirements for structural concrete. Farmington Hills, MI: American Committee Institute

Committee BD-002 (2009). Concrete structure AS 3600-2009: Australian standard for concrete structures. Sydeny: SAI Global Limited.

Craeye, B., Geirnaert, M., and Schutter, G. D. (2011). Super absorbing polymers as an internal curing agent for mitigation of early-age cracking of highperformance concrete bridge decks. Constr. Build. Mater. 25 (1), 1-13. doi:10.1016/j.conbuildmat.2010.06.063

European Committee for Standardization (2004). EN 1992-1-1:2004: Eurocode 2: design of concrete structures part1-1: general rules and rules for buildings. Brussels, Belgium: European Committee for Standardization

Guo, S (2016). Influence of super absorbent polymer on the properties of pavement concrete. Doctoral Thesis. Handan, China: Hebei University of Engineering

$\mathrm{Hu}, \mathrm{S}$., Peng, B., and Wang, F. (2008). Effect of super absorbent polymer particles on autogenous shrinkage and compressive strength of concrete. Huazhong University of Science and Technology (Urban Science Edition). 25 (01), 1-4+16. doi:10.3969/ j.issn.2095-0985.2008.01.001.

International Federation for Structural Concrete (2010). CEB-FIP-2010: fib model code for concrete structures.

Jensen, O. M., and Hansen, P. F. (2001). Water-entrained cement-based materials I. Principles and theoretical background. Cem. Concr. Res. 31 (4), 647-654. doi:10.1016/S0008-8846(01)00463-X

Jensen, O. M., and Hansen, P. F. (2002). Water-entrained cement-based materials: II. Experimental observations. Cem. Concr. Res. 32 (6), 973-978. doi:10.1016/ S0008-8846(02)00737-8

Kong, X, and Zhang, Z. (2014). Shrinkage-reducing mechanism of super-absorbent polymer in high-strength concrete. J. Chin. Ceram. Soc. 042 (002), 150-155. doi:10.7521/j.issn.0454-5648.2014.02.4

Laila, L. R, Gurupatham, B. G. A., Roy, K., and Lim, B. P. J. (2020). Effect of super absorbent polymer on microstructural and mechanical properties of concrete blends using granite pulver. Struct. Concr.. online version, 1-18. doi:10.1002/ suco.201900419

Li, X., Wang, Q., and Wang, Y. (2019). Influence factors and prediction methods for flexural strength of recycled aggregate concrete. J. Build. Struct. 40 (01), 155-164. doi:10.14006/j.jzjgxb.2019.01.018

Liu, J., Farzadnia, N., and Shi, C. (2020). Effects of superabsorbent polymer on interfacial transition zone and mechanical properties of ultra-high performance concrete. Constr. Build. Mater. 231, 117142. doi:10.1016/j.conbuildmat.2019.117142

Ma, Y. (2015). Experiment study on mechanical properties of SAP concrete. doctoral thesis. Tianjin, China: Tianjin University

Mechtcherine, V., and Reinhardt, H.-W.. (2012). Application of super absorbent polymers $(S A P)$ in concrete construction. Dresden, Netherlands: Springer Netherlands

Mechtcherine, V., Gorges, M., Schroefl, C., Assmann, A., Brameshuber, W., Ribeiro, A. B., et al. (2014). Effect of internal curing by using superabsorbent polymers (SAP) on autogenous shrinkage and other properties of a high-performance finegrained concrete: results of a RILEM round-robin test. Mater. Struct. Constr. 47 (3), 541-562. doi:10.1617/s11527-013-0078-5

Mechtcherine, V. (2016). Use of superabsorbent polymers (SAP) as concrete additive. RILEM Tech. Lett. 1, 81-87. doi:10.21809/rilemtechlett.2016.18

Ministry of housing and urban-rural development of the People's Republic of China \& general administration of quality supervision, inspection and quarantine of the People's Republic of China (2003). GB/T 50081-2002: Standard for test method of mechanical properties on ordinary concrete. Beijing, China: China Architecture \& Building Press
Ministry of housing and urban-rural development of the People's Republic of China [MOHURD] (2010). GB 50010-2010: code for design of concrete structures. Beijing, China: China Architecture \& Building Press

Ministry of Transport of the People's Republic of China (2014). JTG/T F30-2014: Technical Guidelines for construction of Highway cement concrete pavements. Beijing, China: China Communications Press

Philleo, R. E. (1991). “Concrete science and reality," in Materials Science of concrete II. Westerville, $\mathrm{OH}$ : American Ceramic Society, 1-8

Powers, T. C., and Brownyard, T. L. (1946). Studies of the physical properties of hardened portland cement paste. J. Am. Concr. Inst. 43 (9), 249-336. doi:10. $14359 / 8745$

Raphael, J. M. (1984). Tensile strength of concrete. J. Am. Concr. Inst. 81 (2), 158-165. doi: $10.14359 / 10653$

Shen, D., Shi, H., Tang, X., Ji, Y., and Jiang, G. (2016). Effect of internal curing with super absorbent polymers on residual stress development and stress relaxation in restrained concrete ring specimens. Constr. Build. Mater. 106, 512-522. doi:10.1016/j.conbuildmat.2016.05.048

Tong, Y. (2018). Research on effect of superabsorbent polymer on performance of cement mortar. Doctoral Thesis. Hangzhou, China: Zhejiang University

Wang, L., Guo, F., Yang, H., Wang, Y., and Tang, S. (2020a). Comparison of FLY ASH, PVA fiber, mgo and shrinkage-reducing admixture on the frost resistance of face slab concrete via pore structural and fractal analysis. Fractals. Accepted manuscript. doi:10.1142/S0218348X21400028

Wang, L, Jin, M, Guo, F, Wang, Y., and Tang, S. (2020b). Pore structural and fractal analysis of the influence of FLY ASH and silica fume on the mechanical property and abrasion resistance of concrete. Fractals. Accepted manuscript. doi:10.1142/S0218348X2140003X

Wang, L, Luo, R, Zhang, W., Jin, M., and Tang, S. (2020c). Effects of fineness and content of phosphorus slag on cement hydration, permeability, pore structure and fractal dimension of concrete. Fractals. Accepted manuscript. doi:10. 1142/S0218348X21400041

Weng, Z., Huang, Z., and Chen, G. D. (2002). Structure and water mechanisms of superabsorbent resin. N. Chem. Mater. 030, 19-21. doi:10.3969/j.issn.10063536.2002.03.005

Wyrzykowski, M., Igarashi, S. I., Lura, P., and Mechtcherine, V. (2018). Recommendation of RILEM TC 260-RSC: using superabsorbent polymers (SAP) to mitigate autogenous shrinkage. Mater. Struct. Constr. 51 (1355). doi:10.1617/s11527-018-1241-9

Xiao, J., and Li, J. (2005). Study on relationships between strength indexes of recycled concrete. J. Build. Mater. 2005 (02), 197-201. doi:10.3969/j.issn.10079629.2005.02.017

Zhang, Z. (2019). Influence and mechanism of SAP on the properties of cement concrete. Doctoral Thesis. Changchun, China: Jilin University

Zheng, W., Kwan, A. K. H., and Lee, P. K. K. (2001). Direct tension test of concrete. ACI Mater. J. 98 (1), 63-71. doi:10.14359/10162

Conflict of Interest: The authors declare that the research was conducted in the absence of any commercial or financial relationships that could be construed as a potential conflict of interest.

Copyright (c) 2020 Xie, Cai, Zhang and Ruan. This is an open-access article distributed under the terms of the Creative Commons Attribution License (CC $B Y)$. The use, distribution or reproduction in other forums is permitted, provided the original author(s) and the copyright owner(s) are credited and that the original publication in this journal is cited, in accordance with accepted academic practice. No use, distribution or reproduction is permitted which does not comply with these terms. 